\title{
Applying Warming Measures on prevention Hypothermia among Parturient Women during Caesarean Delivery
}

\author{
Nahed Fikry Hassan Khedr ${ }^{1, *}$,Maher Shams eldeen ${ }^{2}$ \\ ${ }^{I}$ Woman,s Health and Midwifery Nursing, Faculty of Nursing, \\ ${ }^{2}$ Obstetrics and Gynecology, Faculty of Medicine, \\ ${ }^{1,2}$ Mansoura University, Egypt. \\ Email address:dr.nahid2020@hotmail.com
}

\begin{abstract}
Decrease body temperature during caesarean Section (CS)is happened due to administered intravenous fluids and thermoregulation mechanism disorders it will lead to increase in oxygen consumption, heart rate, blood pressure, pain. The study aimed to evaluate the effect of applying warming measures on prevention hypothermia among parturient women during caesarean delivery.

Methods: A quasi-experimental design was conducted on 60 parturient women candidates for elective cesarean delivery at Obstetrics Operating Room in Mansoura University Hospital from February to July 2016, divided randomly into two groups, the intervention group were (Appling warming measures), and control group were (received routine measures). Data were collected by two tool ( A structured Interviewing Questionnaire, Scale of Shivering and record to follow temperature.

Results : revealed that the baseline temperature were stable in both group but it decreased within 30 min of starting the cesarean section in control group and it was highly statistically significant differences, with P-value $<0.001$. frequency of shivering as considered via Wrench's scale was $27(90 \%)$ of women in the intervention group had no shivering at score zero compared to 18(60\%) of women in the control group during the time spent in the recovery room.
\end{abstract}

Conclusion: The study concluded that intra-operative warmed measures prevent hypothermia and shivering in parturient women undergoing cesarean delivery .

Key Word :Cesarean Delivery, Hypothermia, Anesthesia.

\section{Introduction}

Hypothermia is defined as central body temperature below $36 \mathrm{C}$. It often occurs during anesthesia and CS. (Locks, 2012). Temperature is one of the physiological parameters of the human body. Thermoregulatory system of women ranges from $0.2^{\circ} \mathrm{C}$ to $0.4^{\circ} \mathrm{C}$ around $37^{\circ} \mathrm{C}$ to keep metabolic role (Galvão et al., 2010).Many jeopardy factors for Intraoperative hypothermia, such as gender ,age, anesthetic techniques, length, kind of surgery, women under weight, chronic diseases, cold fluids infusion and operating room temperature if parturient exposure to cold environment in operating rooms, (Kiakkas et al., $2005 \boldsymbol{\&}$ Crowley \& Buggy, 2008).In addition to the size of body cavity exposure, patient with preoperative systolic blood pressure below $140 \mathrm{mmHg}$, trauma, diminished metabolism, sepsis and burns, all of these caused direct inhibition of thermoregulation by anesthetic and it may cause hypothermia (Locks, 2012, Hooper et al., 2010; Torossian, 2008; Burns et al., 2009).

After initiation of anesthesia, vasoconstriction mechanism which is in charge for sustain temperature is reserved, so, vasodilatation occurs lead to increase blood flow to the extremities, body heat is lost more faster and the woman becomes hypothermic (Hussein, 2011). With loco-regional anesthesia, a peripheral vasoconstriction is observed below the level of blockade, which also results in body heat loss, so deregulation of temperature is most associated with combination of these two types of anesthesia (Campbell, 2008; Burns et al., 2009; Kamal \& Hussein, 2011).

Hypothermia can lead to numerous outcomes such as, wound infection, blood loss, blood transfusion thermal discomfort and increase in post-anesthetic recovery. (Kurz, 2008). Post - cesarean section shivering is unlikable and distressful disorders; parturient women who received spinal or general anesthesia complained from chills and shivering (Crowley\& Buggy, 2008). Shivering had been reported among postoperative patient by about $40 \%$ (Miller et. al., 2010).

Many nursing interventions can be used to reduce intra-operative hypothermia, due to skin heat loss, cold operating room and surgical incision. Using of warm infusion fluid, application of patient warming through 
application of patient warming system through water circulation, warming the skin through warm covers and humidifying the air way .

\section{Significance of the Study:}

Abdominal incisions and wetting surgical covers with blood and amniotic fluid, in addition to exposure of parturient women's to anesthesia during CS causes reduction in temperature because of their affect on body thermoregulation mechanisms (Biceret. et al. 2006). It has been proven that Intraoperative hypothermia is related to increase happening infection of wound $3.25 \%$, larger Intraoperative bleeding 1.33\%, necessitate for blood transfusion, and postoperative shivering (Kurz, 2008\&Torossian et. al., 2015).

Maintaining body temperature has been established to decrease postoperative length of hospital stay by as much as $40 \%$ and has been shown to decrease the risk of surgical site infections by $64 \%$ (Weirich, 2008). So this study aimed to evaluate the effect of applying warming measures on prevention hypothermia among parturient women during caesarean delivery.

\section{Aim of the Study:}

This study aimed to evaluate the effect of applying warming measures on prevention hypothermia among parturient women during caesarean delivery.

\section{Research Hypothesis:}

Warming measures for parturient women will maintain body temperature during cesarean delivery.

\section{Materials \& Method}

Research Design: A quasi-experimental design was used.

Research Setting: The study was carried out in Obstetrics Operating Room at Mansoura University Hospital from February to July 2016.

Subjects of the Study: Purposive sample was used on 60 parturient women selected as candidates for elective caesarean delivery according to inclusion criteria and randomly assigned into two groups (Intervention \& Control).

\section{Inclusion Criteria:}

- Normal body temperature

- Gestational age 37-42 weeks

- Cesarean delivery.

- Age of parturient women 20 and 40 years

- Free from any medical diseases.

\section{Tools of Data Collection}

Tool( I) Interviewing Questionnaire: It is consisted of three parts as follows:

Part (1) General Characteristics of parturient women such as (age, level of education, occupation, residence, height and body weight etc ........).

Part (2) Obstetrical History such as (Gravidity, parity, mode of labor, , gestational age, etc.......)

Part (3) Data regarding present Cesarean delivery as(Indication of cesarean section, type of anesthesia, drugs used in anesthesia, type of intravenous fluids and it's amount, duration of cesarean section) .

Tool II Scale of Shivering: It was adopted from (Wrench et al., 1997)

The scoring system of the tool has been used to assess shivering grade during and after Cesarean Section as zero (0) for no shivering; one for one or more of the following: peripheral vasoconstriction ,peripheral cyanosis without other cause two for visible muscular activity confined to one muscle group and four for gross muscular activity involving the whole body. This scale (Scale of Shivering) tool was translated into Arabic and reviewed by jury consisted of 3 expertise in the field of the study to test its contents and face validity.

\section{Tool( III) Recording of body temperature}


As preoperative body temperature, Intra-operative body temperature within (5minutes, 10 minutes, 15 minutes, 30 minutes).

\section{Pilot Study}

Pilot study was carried out on $10 \%$ of the sample size (6 parturient women) to test the clarity, applicability, simplicity and feasibility of the developed tools and the necessary modification was done the pilot sample was excluded from the study.

\section{Field Work}

The study period was consumed six months, started from February 2016 until July 2016. Official permission was obtained from the Head of the obstetrics and Gynecology Department, Mansoura University Hospital. Phases of this study implemented in three places as follows:

\section{(1) Waiting room for the operation:-}

Aim of study explained, acquire informed permission for participation in the study, history taken and initial assessment was performed. Pregnant women undergoing elective cesarean section were selected according to inclusion criteria and then separated into two equal groups( intervention and control ). Body temperature measured and recorded for both groups.

\section{(2) At the operating room:}

After parturient women entered operating room, the researcher applied warming measures for intervention group such as(warmed intravenous fluids at $\left(40^{\circ} \mathrm{C}\right)$ such as "saline or ringer lactate", asked women to wear heavy gown, long socks, cap on the head, covering by double linen ).The control group just received the routine preoperative care. All studied groups were assessed for core body temperature within 5, 10, 15\& 30 minutes from beginning operation, as well as degree of shivering was also assessed.

\section{(3) Recovery room :}

After women transferred to recovery room, researcher assessed core body temperature for both groups within $5,10,15 \& 30$ minutes of operation, as well as degree of shivering was also assessed.

\section{Data Analysis}

Data entry and statistical analysis was done using Statistical Packages for Social Science (SPSS) version 18.0. Data were presented using descriptive statistics in the form of frequencies and percentages for qualitative variables, means and standard deviations for quantitative variables. Qualitative variables were compared using chi-square test. Quantitative variable were compared using t test. Statistical significance was considered at p-value $\leq 0.05$ (Krzywinski\& Altman, 2013).

\section{Results}

Table (1) Demonstrates the general characteristics of the women groups.

There were no statistical significant differences regarding age, weight, height \& gestational age among control and intervention groups ( $\mathrm{p}>0.05)$.

Table (2)Presents the general characteristics of the women groups. There were no statistical significant differences regarding marital status, residence \& educational level among control and intervention groups ( $\mathrm{p}$ $>0.05)$

Table (3)Shows there were no statistical significant differences among intervention and control groups according to their obstetrical history $(\mathrm{p}>0.05)$

Table (4)Reveals there were no statistical significant differences among intervention and control groups regarding total fluids, duration of surgery $(\mathrm{p}>0.05)$. Concerning preoperative core temperature among intervention and control groups, the baseline mean core temperature was $37.23 \pm 0.29^{\circ} \mathrm{C}$ and $37.09 \pm$ $0.51^{\circ} \mathrm{C}$, respectively. There was no statistical difference between the two groups.

Table (1) Mean and Standard Deviation of the Studied Groups according to their General Characteristics.

\begin{tabular}{l|l|l|l}
\hline \hline Items & \multicolumn{1}{|c|}{$\begin{array}{c}\text { Study group } \\
(\mathbf{n = 3 0})\end{array}$} & \multicolumn{1}{c}{$\begin{array}{c}\text { Control Group } \\
(\mathbf{n = 3 0})\end{array}$} & p- value \\
& \multicolumn{1}{|c|}{ Mean $^{ \pm} \mathbf{S D}$} & Mean $^{ \pm}$SD & \\
\cline { 2 - 4 } & & $27.90 \pm 4.12$ & 0.26 \\
\hline \hline Age & $26.53 \pm 5.23$ & $76.46 \pm 9.87$ & 0.82 \\
\hline Height & $75.86 \pm 10.69$ & $160.03 \pm 3.31$ & 0.4 \\
\hline Gestational Age & $159.2 \pm 3.83$ & $36.53 \pm 2.29$ & 0.30 \\
\hline \hline
\end{tabular}


Applying Warming Measures on prevention Hypothermia among Parturient Women during ..

Table (2) Frequency Distribution of the Studied Groups according to their General Characteristics (Continue).

\begin{tabular}{|c|c|c|c|c|c|c|}
\hline \multirow[t]{2}{*}{ Items } & \multicolumn{2}{|c|}{$\begin{array}{l}\text { Study group } \\
(\mathbf{n}=\mathbf{3 0})\end{array}$} & \multicolumn{2}{|c|}{$\begin{array}{c}\text { Control Group } \\
(n=30)\end{array}$} & \multirow{2}{*}{$\mathbf{X}^{2}$} & \multirow{2}{*}{ P-value } \\
\hline & No. & $\%$ & No. & $\%$ & & \\
\hline $\begin{array}{l}\text { Marital status : } \\
\text { Married }\end{array}$ & 30 & 100.0 & 30 & 100.0 & - & - \\
\hline $\begin{array}{c}\text { Residence : } \\
\text { Rural } \\
\text { Urban }\end{array}$ & $\begin{array}{l}25 \\
5\end{array}$ & $\begin{array}{l}83.3 \\
16.7\end{array}$ & $\begin{array}{l}19 \\
11\end{array}$ & $\begin{array}{l}63.3 \\
36.7\end{array}$ & 3.07 & 0.08 \\
\hline $\begin{array}{l}\text { Educational level : } \\
\text { Illiterate } \\
\text { Preparatory } \\
\text { Secondary } \\
\text { Middle education } \\
\text { Higher education }\end{array}$ & $\begin{array}{l}2 \\
4 \\
16 \\
3 \\
5\end{array}$ & $\begin{array}{l}6.7 \\
13.3 \\
53.3 \\
10.0 \\
16.7\end{array}$ & $\begin{array}{l}1 \\
2 \\
18 \\
9 \\
0\end{array}$ & $\begin{array}{l}3.3 \\
6.7 \\
60.0 \\
30.0 \\
0.0\end{array}$ & 9.12 & 0.06 \\
\hline
\end{tabular}

Table (3): Frequency Distribution of the Studied Groups according to their Obstetrical History.

\begin{tabular}{|c|c|c|c|c|c|c|}
\hline \multirow[t]{2}{*}{ Items } & \multicolumn{2}{|c|}{$\begin{array}{c}\text { Study Group } \\
(\mathrm{n}=30)\end{array}$} & \multicolumn{2}{|c|}{$\begin{array}{c}\begin{array}{c}\text { Control Group } \\
(n=30)\end{array} \\
\text { con }\end{array}$} & \multirow{2}{*}{$X^{2}$} & \multirow{2}{*}{$\begin{array}{c}P \text { - } \\
\text { value }\end{array}$} \\
\hline & No. & $\%$ & No. & $\%$ & & \\
\hline $\begin{array}{c}\text { Gravida } \\
\text { Primi } \\
\text { Multi }\end{array}$ & $\begin{array}{l}17 \\
13\end{array}$ & $\begin{array}{l}56.7 \\
43.3\end{array}$ & $\begin{array}{l}15 \\
15\end{array}$ & $\begin{array}{l}50.0 \\
50.0\end{array}$ & 0.67 & 0.7 \\
\hline $\begin{array}{c}\text { Parity } \\
\text { Primi } \\
\text { Multi } \\
\end{array}$ & $\begin{array}{l}17 \\
13\end{array}$ & $\begin{array}{l}56.7 \\
43.3\end{array}$ & $\begin{array}{l}15 \\
15\end{array}$ & $\begin{array}{l}50.0 \\
50.0\end{array}$ & 0.29 & 0.9 \\
\hline $\begin{array}{l}\text { Causes of Caesa } \\
\text { Section } \\
\text { Previous C.S. } \\
\text { Elective C.S. }\end{array}$ & $\begin{array}{l}5 \\
25\end{array}$ & $\begin{array}{l}16.7 \\
83.3\end{array}$ & $\begin{array}{l}9 \\
21\end{array}$ & $\begin{array}{l}30.0 \\
70.0\end{array}$ & 1.49 & 0.22 \\
\hline
\end{tabular}

Table (4): Mean and standard Deviation of the Studied Groups according to Total Fluids \& Duration of Surgery.

\begin{tabular}{l|l|c|l|l}
\hline \hline \multirow{2}{*}{ Items } & $\begin{array}{c}\text { Intervention Group } \\
(\mathbf{n = 3 0})\end{array}$ & $\begin{array}{c}\text { Control Group } \\
(\mathbf{n}=\mathbf{3 0})\end{array}$ & T test & P value \\
\cline { 2 - 5 } & \multicolumn{1}{|c|}{ Mean $^{ \pm}$SD } & Mean $^{ \pm}$SD & & \\
\hline \hline Total Fluids(ml) & $1.366^{ \pm} 224.88$ & $1.383^{ \pm} 215.09$ & 0,29 & 0,77 \\
\hline Duration of Surgery & $46.50^{ \pm} 5.11$ & $48.66^{ \pm} 6.01$ & 1.50 & 0.14 \\
\hline Preoperative Core Temperature & $37.23^{ \pm} 0.29$ & $37.03^{ \pm} 0.51$ & 1.88 & 0.07 \\
\hline \hline
\end{tabular}




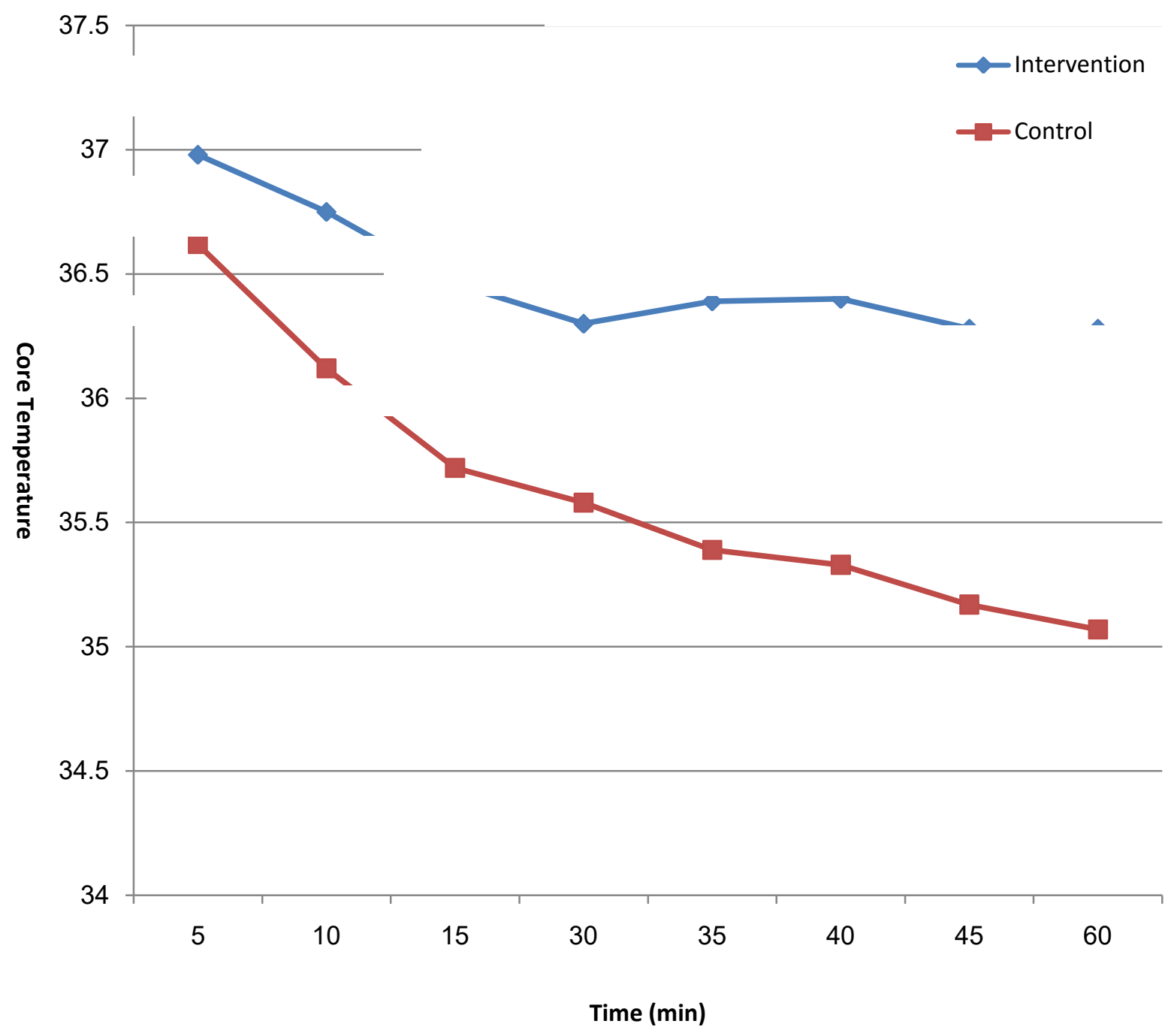

Figure 1: Trends in mean core temperature $\left({ }^{\circ} \mathrm{C}\right)$ in the two study groups.

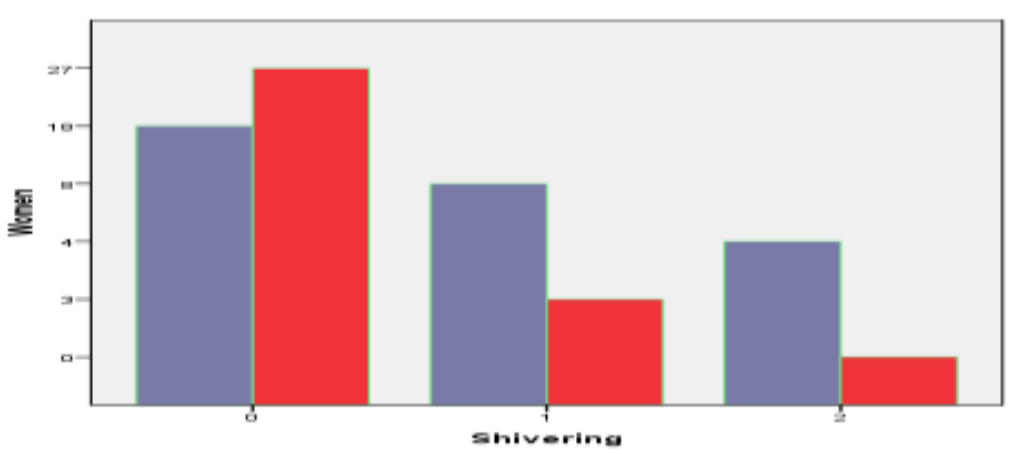

Figure 2: Distribution of parturient Women according to Intensity of Shivering for Wrench's scale.

\section{Discussion}

Aim of this study was to evaluate the effect of applying warming measures on prevention hypothermia among parturient women during caesarean delivery. This aim was significantly supported with the present hypothesis. This study was conducted 60 parturient women selected as candidates for elective caesarean delivery according to inclusion criteria and divided into two equal groups (Intervention \& Control), and both were almost similar regarding the general 
Applying Warming Measures on prevention Hypothermia among Parturient Women during ..

characteristics with no statistically any significant differences. Additionally, the present study findings revealed no significant differences among intervention and control groups as regards degree of body temperature at baseline; while after induction anesthesia, ,there were major variation among both groups.. Accordingly, the study hypothesis is accepted.

The present study finding showed that utilizing warming measures for parturient women for intervention group such as(warmed intravenous fluids at $\left(40^{\circ} \mathrm{C}\right)$ such as "saline or ringer lactate", asked women to wear heavy gown ,long socks, cap on the head ,covering by double linen were associated with maintaining body temperature among intervention group compared to those of the control group . Hypothermia is the temperature below $36^{\circ} \mathrm{C}$. Parturient women are at risk of developing hypothermia after CS due to many factors such as heat loss due to cool operating room, the infusion of cool fluids (Goyal et al., 2011). Mild hypothermia may lead to numerous complications such as surgical wound infections, serious myocardial outcomes and coagulopathy (Horn et al., 2002). Shivering can be as high as $60 \%$ in obstetric parturient women's (Reynolds et al., 2008).

Several ways have been performed to assist and keep normal body temperature during CS., as warm parturient women's before inducing anesthesia, forced-air system is by far the most usually utilized intraoperative warming methods. However, blanket-forced air warming, circulating-water gar-ments, or water mattresses do not simply permit the shifting of position on the bed, particularly when the parturient women is in sitting position(de Bernardiset. al., 2015).So. the study designed to evaluate the effect of applying warming measures on prevention hypothermia among parturient women during caesarean delivery. The present study showed that mean age of the mothers in intervention and control groups were $26.53 \pm 5.23 \& 27.90 \pm 4.12$ respectively, this in line with Goyal et.al., 2011 who studied efficacy of intravenous fluid warming for maintenance of core temperature during lower segment cesarean section under spinal anesthesia and found that mean age of mothers among group I (control) \& group II (intervention) were $27.16 \pm 4.30 \& 26.84 \pm 5.77$ respectively.

As regards comparison temperature among intervention and control groups, fluid warming lead to decrease occurrence of hypothermia as contrast with intravenous of parturient women into intervention group was higher than parturient women in control grouping from baseline on 5, 10, 15, 30, 35, 40, 55 \& 60 minutes. Warming intravenous fluids lead to decrease heat losses and attainment of the plateau phase of thermoregulatory responses. This is due to positive effect of warming measures for the intervention group.

This is in conformity with Smith, et al., 2000, who confirmed that epidural anesthesia reduce the shivering threshold and raise leg temperature and also as the same line with Smith et al., 1998 who revealed that applying warming measures kept body temperature and increased the core temperature by $0.5-0.7^{\circ} \mathrm{C}$ and lessened the rate of hypothermia in women undergoing gynecological surgery.

Correspondingly, Yokoyama et al., 2009 studied the effect of pre-warmed intravenous fluids administration on hypothermia occurrence after cesarean delivery by spinal anesthesia; they confirmed maintenance of body temperature at normal value after receiving pre-warmed fluids.

According to intensity of shivering, result of this study showed a statistical significant decrease in intensity of shivering at score zero\& score two of Wrench's scale of shivering among intervention \& control groups. The researchers interpreted that less fall in core temperature of the intervention group result in low intensity of shivering compared to control group.

Similarly, Chung et al., (2012), had studied the effect of preoperative warming during cesarean delivery under spinal anesthesia and illustrated that preoperative forced air-warming and warmed fluid prevented maternal core hypothermia and reduces maternal shivering in parturient women during cesarean section under spinal anesthesia.

This agreement with( Aglio et al, 1988), they founded that temperature maintained and a significantly reduced Prevalence of shivering when women receiving warm IV, fluids versus at room temperature. Meanwhile Goyal et.al., (2011) , had conducted study to assess efficacy of intravenous fluid warming for maintenance during lower segment cesarean section under spinal anesthesia, found that advantage of a reduction in rate of shivering was however not observed in his study. The finding of the current study contradict Woolnough et al., 2009 in their study about in Intra-operative fluid warming in elective caesarean section: a blinded randomized controlled trial, They showed that pre-warmed fluids did not affect shivering.

\section{Conclusion}

Some important facts can be concluded into: the present study findings revealed no significant differences among the intervention and control groups regarding degree of body temperature at baseline; while after induction anesthesia ,there were significant differences among the two groups.

\section{Recommendations}

Based on the findings of the present study the following were recommended:

- Applying of warmed intravenous fluids as nursing intervention for preventing hypothermia and shivering for parturient women undergoing for elective cesarean section. 
- Implement training programs for nurses regarding important of Applying of warmed intravenous fluids as nursing intervention for preventing hypothermia and shivering for parturient women undergoing for elective cesarean section.

- An application prophylactic methods to keep body temperature stable for women undergoing elective cesarean section

\section{Acknowledgments}

I would like to thank all women for their participation in this study and all staff members (nursing, obstetricians and anesthesiologists staff) at Obstetrics Operating Room at Mansoura university hospital for their cooperation to complete this study.

[1]. Aglio LS, Johnson MD, Datta S, Ostheimer GW. (2008):Warm intravenous fluids reduce shivering in parturient receiving epidural analgesia. Anesthesiology;69:A701.Anaesthesiol,;22:39-62

[2]. Bicer C, Esmaoglu A, Akin A, Boyaci A. (2006): Dexmetomidine and meperidine prevent postanesthesia shivering. Eur J Anesthesiol;23:149-53. [PubMed]

[3]. Burns, S., Piotrowski, K., Caraffa, G., \&Wojnakowski, M. (2009): Unintentional hypothermia: Implications for pre anesthesia nurses. Journal of Pre Anesthesia Nursing, 24(3), 167-173. doi: 10.1016/j.jopan.03.003

[4]. Campbell, L. (2008).Body temperature and its regulation. Anaesthesia\& Intensive Care Medicine, 9(6), 259-263. doi: 10.1016/j.mpaic.2008.04.009

[5]. Chung SH, Lee BS, Yang HJ, Kweon KS, Kim HH, Song J, et al. (2012): Effect of preoperative warming during cesarean section under spinal anesthesia. Korean J Anesthesiology;62:454-60. [PMC free article] [PubMed

[6]. Crowley LJ, Buggy DJ. ( 2008):Shivering and neurexial anesthesia.RegAnesth Pain Med;33:241-52. [PubMed]

[7]. deBernardisRCd., Siaulys MM., Vieira JE., et.al. (2015): Perioperative warming with a thermal gown preventsmaternal temperature loss during elective cesareansection.A randomized clinical trial Rev Bras Anestesiol. http://dx.doi.org/10.1016/j.bjane.2014.12.007

[8]. Galvão, C., Liang, Y., \& Clark, A. (2010):Effectiveness of cutaneous warming systems on temperature control: Metaanalysis. Journal of Advanced Nursing, 66(6), 1196-1206. doi: 10.1111/j.1365-2648.2010.05312.x

[9]. Goyal P, Kundra S, Sharma S, Grewal A, Kaul TK, Singh MR. (2011): Efficacy of intravenous fluid warming for maintenance of core temperature during lower segment cesarean section under spinal anesthesia. J ObstetAnaesthCrit Care;1:73-7.

[10]. Hooper, V., Chard, R., Clifford, T., Fetzer, S., Fossum, S., Godden, B., Wilson, L. (2010): ASPAN's evidence-based clinical practice guideline for the promotion of preoperative normothermia: Second edition. Journal of Pre Anesthesia Nursing, 25(6), 346-365. doi: 10.1016/j.jopan.2010.10.006

[11]. Horn EP, Schroeder F, Gottschalk A, Sessler DI, Hiltmeyer N, Standl T, et al. (2002): Active warming during cesarean delivery. AnesthAnalg;94:409-414. [PubMed]

[12]. Hoseinkhan Z, Behzadi M. (2007): Morphine, Pethidine and Fentanyl in postoperative shivering control: A randomized clinical trial. Tehran Univ Med J;64:57-63.

[13]. Kamal, M., \& Hussein, N. (2011):Prevention of post spinal shivering by using ketamine plus midazolam in comparison with nefopam. Egyptian Journal of Anaesthesia, 27(1), 1-5. doi: 10.1016/j.egja. 12.002

[14]. Kiakkas P, Poulopoulou M, Papahatzi A, Souleles P. (2005): Effect of hypotermia and shivering on standard PACU monitoring of parturient women's. AANA J.;73:47-53. [PubMed]

[15]. Krzywinski, \&N. Altman, (2013): "Points of significance, P values and t-tests", Nat. Method, 10, 809-810.

[16]. Kurz A (2008): Thermal care in the preoperative period. Best Pract Res Clin . Anaesthesiol,;22:39-62.

[17]. Locks G. Df. (2012): Incidence of Shivering after Cesarean Section under Spinal Anesthesia with or without Intrathecal Sufentanil:A Randomized Study. Rev Bras Anestesiol; 62: 5: 676-684

[18]. Miller RD, Eriksson LI, Fleisher LA, Wiener-Kronish JP, Young WL. (2010): 7th ed. New York: Churchill Livingstone; Miller's Anesthesia.

[19]. Reynolds L, Beckmann J, Kurz A. (2008): Preoperative complications of hypothermia. Best Pract Res Clin Anaesthesiol.;22:645---57.17

[20]. Smith CE, Fisgus JR, Kan M, Lengen SK, Myles C, Jacobs D, et al.( 2000): Efficacy of IV fluid warming in parturient women's undergoing cesarean section with regional anesthesia. Am J Anesthesiol;27:84-8

[21]. Smith CE, Gerdes E, Sweda S, Myles C, Punjabi A, Pinchak AC, et al. (1998): Warming intravenous fluids reduces preoperative hypothermia in women undergoing ambulatory gynecological surgery. Anesth Analg;87:37-41.

[22]. Torossian A., BräuerA.,HöckerJ., BeinB., Wulf H., et. al.,(2015): Preventing Inadvertent Preoperative Hypothermia .Deutsches Ärzteblatt International | DtschArzteblInt 2015; 112: 166-72

[23]. Torossian, A. (2008):Thermal management during anaesthesia and thermoregulation standards for the prevention of inadvertent preoperative hypothermia. Best Practice and Research Clinical Anaesthesiology, 22(4), 659-668. doi: 10.1016/j.bpa. 07.006

[24]. Weirich TL. (2008): Hypothermia/warming protocols: why are the not widely used in the OR? AORN J.;87(2):333-344

[25]. Woolnough M, Allam J, Hemingway C, Cox M, Yentis SM. (2009): Intraoperative fluid warming in elective caesarean section: a blinded randomized controlled trial. Int J ObstetAnesth;18:346-351. [PubMed]

[26]. Wrench IJ, Cavill G, Ward JE, Crossley AW. (1997): Comparison between alfentanil, pethidine and placebo in the treatment of post-anaesthetic shivering.Br J Anaesth; 79: 541-2.

[27]. Yokoyama K, Suzuki M, Shimada Y, Matsushima T, Bitto H, Sakamoto A. (2009): Effect of administration of prewarmed intra venous fluids on the frequency of hypothermia following spinal anesthesia for cesarean delivery. J Clin Anesth;21:242-8. 